\title{
GPR UTILIZADO NA DETEÇÃO DA GEOMETRIA DE CAVAS USADAS PARA DISPOSIÇÃo DE RESÍDUOS DE ÓLEOS LUBRIFICANTES
}

\author{
Welitom Borges ${ }^{1}$, Alexandre Lago ${ }^{1}$, Sergio Fachin ${ }^{1}$, Vagner Elis ${ }^{2}$ e Ernande Santos ${ }^{3}$ \\ Recebido em 10 abril, 2006 / Aceito em 28 dezembro, 2006 \\ Received on April 10, 2006 / Accepted on December 28, 2006
}

\begin{abstract}
A variety of environmental problems occurs due to the inadequate disposition of residues. Applied geophysics methodologies to environmental studies show great results in the investigation of contaminating. GPR is a practical and fast geophysical method in such investigations, because the electromagnetic signal assists in the delimitation of the contaminating, addressing direct techniques of investigation (boreholes and wells). This study was developed in an old disposition area to residues lubricants oils (dense nonaqueous phase liquids - DNAPL) in the municipal district of Ribeirão Preto, São Paulo State. This area is situated in the geological domains of the basaltic floods of the Serra Geral Formation and sandstones of the Botucatu Formation. GPR acquisition was carried out inside and next to 4 ditches of residues disposition, with $100 \mathrm{MHz}$ unshielded antennas, enabling a maximum investigation depth of 7 meters. The limits and of the ditches base can be identify in the GPR sections, except in the ditch 1, which the base is not delineated by GPR. The results show that GPR signal is much attenuated below ditches. This fact could be result of a bacteriological activity in the residue or increase of dissolved salts in the soil caused by acid pH of the residue.
\end{abstract}

Keywords: GPR, DNAPL, residues of lubricants oils, contamination, Ribeirão Preto.

RESUMO. Uma variedade de problemas ambientais ocorre devido à disposição inadequada de resíduos. Metodologias geofísicas aplicadas a estudos do meio físico mostram ótimos resultados na investigação de contaminantes. 0 georadar é um método geofísico prático e rápido nestas investigações, pois a resposta do sinal eletromagnético auxilia na delimitação do contaminante em subsuperfície, direcionando técnicas diretas de investigação (furos e poços de monitoramento). Este estudo foi desenvolvido numa antiga área de disposição de resíduos de óleos lubrificantes (dense nonaqueous phase liquids - DNAPL) no município de Ribeirão Preto - SP, situada nos domínios geológicos dos derrames basálticos da Formação Serra Geral e arenitos da Formação Botucatu. A aquisição de seções GPR foi realizada dentro e próximo de 4 cavas de disposição de rejeitos, com antenas não-blindadas de $100 \mathrm{MHz}$, possibilitando uma profundidade de investigação máxima de 7 metros. Os limites laterais e as bases das cavas puderam ser identificados nas seções GPR, com exceção da cava 1, cuja base não é bem caracterizada pelo sinal GPR. Os resultados mostram que o sinal eletromagnético do GPR é bastante atenuado abaixo das cavas. Este fato pode ser resultado de uma atividade bacteriológica no resíduo ou aumento de sais dissolvidos no meio causado pelo pH ácido do resíduo.

Palavras-chave: GPR, DNAPL, resíduos de óleos lubrificantes, contaminação, Ribeirão Preto.

\footnotetext{
${ }^{1}$ Curso de Pós-Graduação em Geofísica. Instituto de Astronomia, Geofísica e Ciências Atmostéricas, Rua do Matão, 1226, Cidade Universitária, 05508-090 São Paulo, SP, Brasil. Tel: (11) 3091-2792 - E-mail: welitom@iag.usp.br, alexandre@iag.usp.br e fachin@iag.usp.br

${ }^{2}$ Departamento de Geofísica, Instituto de Astronomia, Geofísica e Ciências Atmosféricas, Rua do Matão, 1226, Cidade Universitária, 05508-090 São Paulo, SP, Brasil. Tel: (11) 3091-4749; Fax: (11) 30915034 - E-mail: vagnelis@iag.usp.br

${ }^{3}$ Laboratório de Geofísica Aplicada, Instituto de Astronomia, Geofísica e Ciências Atmosféricas, Rua do Matão, 1226, Cidade Universitária, 05508-090 São Paulo, SP, Brasil. Tel: (11) 3091-2765; Fax: (11) 3091-5034 -E-mail: ernande@iag.usp.br
} 


\section{INTRODUÇÃ̃o}

No Brasil, até a década de 70, os resíduos industriais e urbanos eram dispostos diretamente no solo, pois se acreditava que o solo era um receptor ilimitado de substâncias nocivas descartáveis, como o lixo doméstico e os resíduos industriais, com base no suposto poder tampão e potencial de autodepuração (CETESB, 2001). Porém esta capacidade, como comprovado atualmente, foi superestimada, causando danos irrecuperáveis ao meio ambiente.

A contaminação do solo é preocupante porque é nesta camada que cultivamos a maior parte dos alimentos necessários à sobrevivência humana. Além do solo, o contaminante pode atingir 0 lençol freático, e tornar a água imprópria para o consumo.

Os contaminantes são tipicamente dispostos em subsuperfície como constituintes da fase líquida, assim como solução aquosa diluída, solução aquosa concentrada (chorume), ou um líquido orgânico (fase líquida não aquosa ou Nonaqueous phase liquids - NAPL), que é imiscível com água. As características do contaminante influenciam a direção da migração, a extensão da pluma e a persistência do mesmo (Committee on Source Removal of Contaminants in the Subsurface, 2004).

Os NAPL's podem ser classificados em light nonaqueous phase liquids - LNAPL e dense nonaqueous phase liquids DNAPL. Diferenciados principalmente pela densidade, o primeiro é um líquido imiscível em fase não aquosa mais leve que a água, ao passo que 0 segundo é mais denso que a água.

Os NAPL's podem apresentar quatro fases em subsuperfície: vapor (volatilização dos hidrocarbonetos em fase sorvida presente na zona não saturada), adsorvida (retenção de hidrocarbonetos na superfície dos grãos), dissolvida (dissolução dos hidrocarbonetos em contato com a água subterrânea) e separada (fase livre ou residual). Nos DNAPL's, a fase livre flui no sentido do fluxo da água subterrânea, ao passo que a fase residual não tem mobilidade para deslocamento (Figura 1).

Estudos hidrogeológicos mostram que os mecanismos de migração e dispersão de contaminantes são complexos, 0 que torna difícil estimar adequadamente a quantidade ou continuidade destes produtos em subsuperfície, utilizando apenas poços de monitoramento (Freeze \& Cherry, 1979). A Companhia de Tecnologia de Saneamento Ambiental do Estado de São Paulo (CETESB) recomenda, no diagnóstico ambiental de áreas contaminadas, a realização de poços de monitoramento próximos ao resíduo e levantamentos geofísicos na área. Estes têm por objetivo básico a identificação da presença da contaminação subterrânea, além da definição das feições geológicas e hidro- geológicas dos locais investigados (CETESB, 2001). 0 uso dos métodos geofísicos (não invasivos) evita a infiltração do contaminante para camadas não contaminadas e não perturba 0 meio físico. Além disto, os métodos geofísicos conseguem cobrir áreas maiores com custo reduzido, quando comparado com os métodos diretos de investigação.

Os métodos geofísicos mostram excelentes resultados na identificação de locais contaminados por "líquidos imiscíveis em fase não aquosa" - NAPL's (Davis \& Annan, 1989; Benson, 1995; Daniels et al., 1995; Sauck et al., 1998; Vickery \& Hobbs, 1998; Atekwana et al., 2000; Sauck, 2000; Dehaine, 2001; Castro \& Branco, 2003; Penner, 2005).

0 Ground Penetrating Radar (GPR) mostra bons resultados na identificação e monitoramento de plumas de contaminação de hidrocarbonetos. Daniels et al. (1995) monitoraram o comportamento de poças de hidrocarbonetos em um tanque de areia e água com 0 GPR, e verificaram que a amplitude do sinal eletromagnético é menor na parte superior da pluma de hidrocarboneto, podendo ser provocada pela fase residual do mesmo. Benson (1995), em estudos de contaminação, mostra que a gasolina tem forte reflexão nas seções de GPR. Sauck (2000) elaborou um modelo temporal de biodegradação de LNAPL através de dados de resistividade medidos continuamente em poços. 0 mesmo verificou que quanto maior o tempo de exposiçã̃o do resíduo, menor será a sua resistividade e vice-versa. Dehaine (2001) identificou vazamentos de gasolina, em postos de serviço na cidade de São Paulo, utilizando GPR e poços de monitoramento. A autora mostra que 0 contaminante atenua a onda eletromagnética do GPR. Castro \& Branco (2003), usando GPR 4D, monitoraram a evolução de zonas contaminadas por gasolina em um posto de Fortaleza.

Neste trabalho são apresentados resultados da aquisição de seções GPR em uma área de disposição de resíduos de sulfonação de óleos lubrificantes usados (DNAPL). Estes resíduos são compostos por $72 \%$ de óleo lubrificante, 7,5\% de óleo oxidado, 3,1\% de enxofre (ácido sulfúrico) e impurezas 17,4\% (Rosseli, 1995).

0 local deste estudo foi receptor destes resíduos desde meados da década de 60 até 0 ano de 1995. Os resíduos foram dispostos em 4 cavas com dimensões aproximadas de 41 a 49 metros de comprimento, 24 a 36 metros de largura e profundidade média de 6 metros. As cavas não receberam nenhum tipo de impermeabilização e foram recobertas por solo após anos de recepção de resíduos. Penner (2005) realizou amostragens nos resíduos, no solo e em amostras de água coletada em poços. Análises químicas do material retirado de dentro das cavas mostraram que a fração inorgânica do resíduo apresenta elevados per- 


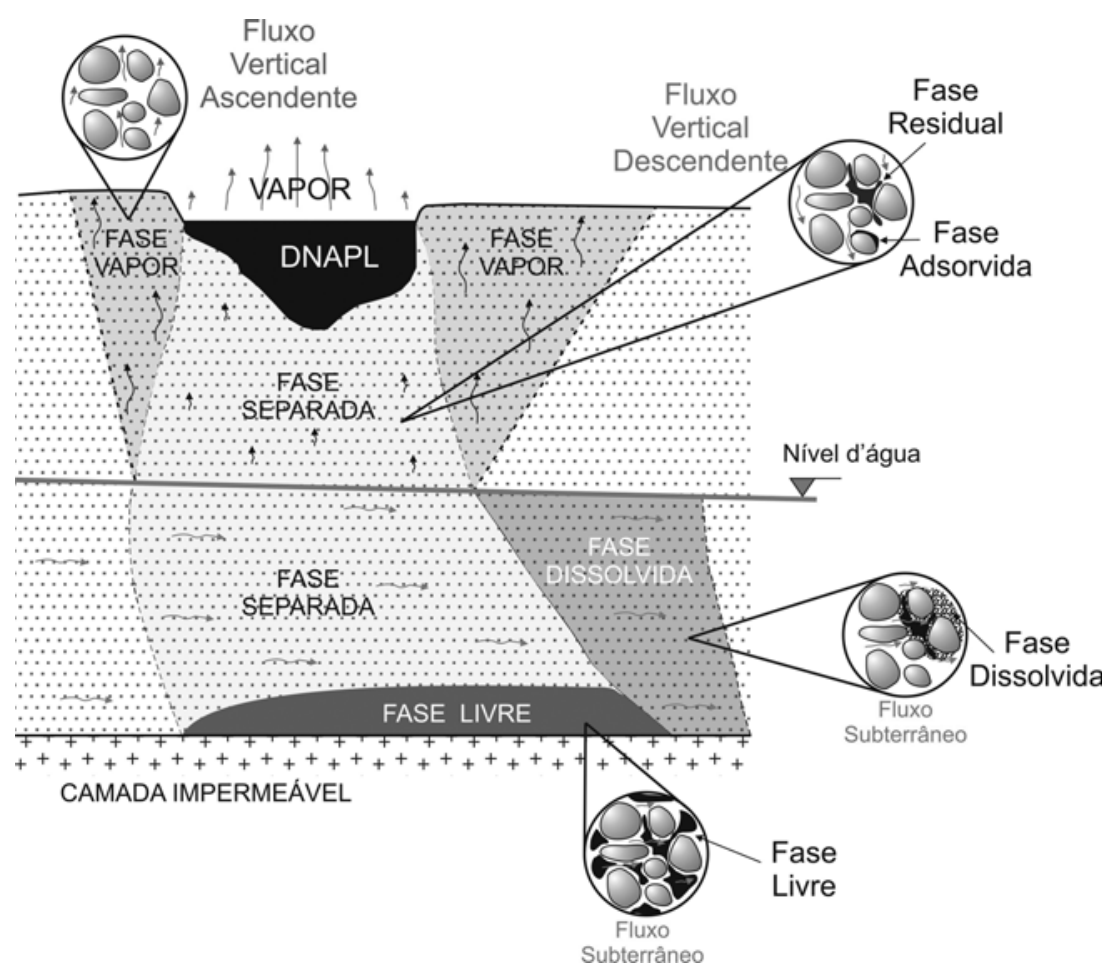

Figura 1 - Representação esquemática do comportamento de DNAPL's em subsuperfície.

centuais de enxofre (20 a 56\%), de cálcio (23 a 35\%), além de elevados percentuais de silício e quantidades não desprezíveis de titânio e chumbo. Em análises de solo do local encontrou em geral baixas concentrações de uma série de hidrocarbonetos policíclicos aromáticos (HPAs), sendo os principais o naftaleno (0,004 ppm, sem padrão de comparação) e o fenantreno (0,04 ppm, padrão de intervenção da CETESB de 0,2 ppm). Nas análises de água coletada em poços de monitoramento na área verificou contaminação da água subterrânea por chumbo (Pb).

A área está localizada próximo ao km 334 da Rodovia Alexandre Balbo (SP 328), município de Ribeirão Preto, estado de São Paulo (Figura 2). Este estudo tem como principal objetivo verificar a potencialidade do método GPR na delimitação da geometria das cavas e o comportamento do sinal EM dentro e abaixo do resíduo.

\section{ASPECTOS GEOLÓGICOS}

A área está situada na Bacia Sedimentar do Paraná, representada por duas unidades geológicas distintas, a Formação Botucatu e Serra Geral.

A Formação Botucatu é a principal unidade do Aqüífero Guarani, responsável pela maior parte do abastecimento da cidade de Ribeirão Preto. A litologia é caracterizada como arenitos finos a muito finos, avermelhados, friáveis, com grãos foscos e arredondados. Na região, ocorre comumente recoberta por basaltos da Formação Serra Geral. Quando aflorante constitui uma zona de recarga do Aqǘfero Guarani. Os basaltos, da Formação Serra Geral, são de textura fina, estrutura maciça a fraturada, ocorre subjacente a um colúvio na região. 0 colúvio é de origem silto-arenoso a silto-argiloso, apresentando coloração variando de roxa a vermelha. São encontrados também nódulos ou crostas de lateritas inseridas no colúvio silto-arenoso. Sua origem pode estar relacionada ao intemperismo das rochas básicas da Formação Serra Geral e enriquecidas da fração arenosa pelo retrabalhamento de solos arenosos da Formação Botucatu na região (Rosseli, 1995).

Penner (2005) identificou, a leste da área, arenitos da Formação Botucatu, através de furos de sondagem e de investigações elétricas, em profundidade superior a 12 metros. Já a Formação Serra Geral é evidenciada na área por fragmentos e solo aluvionar de basalto (Argissolos).

As sondagens mostraram uma camada de argila silto-arenosa de cor vermelha escura até a profundidade máxima de 6 metros, seguida por siltes muito argilosos provenientes da alteração do basalto (Penner, 2005). 


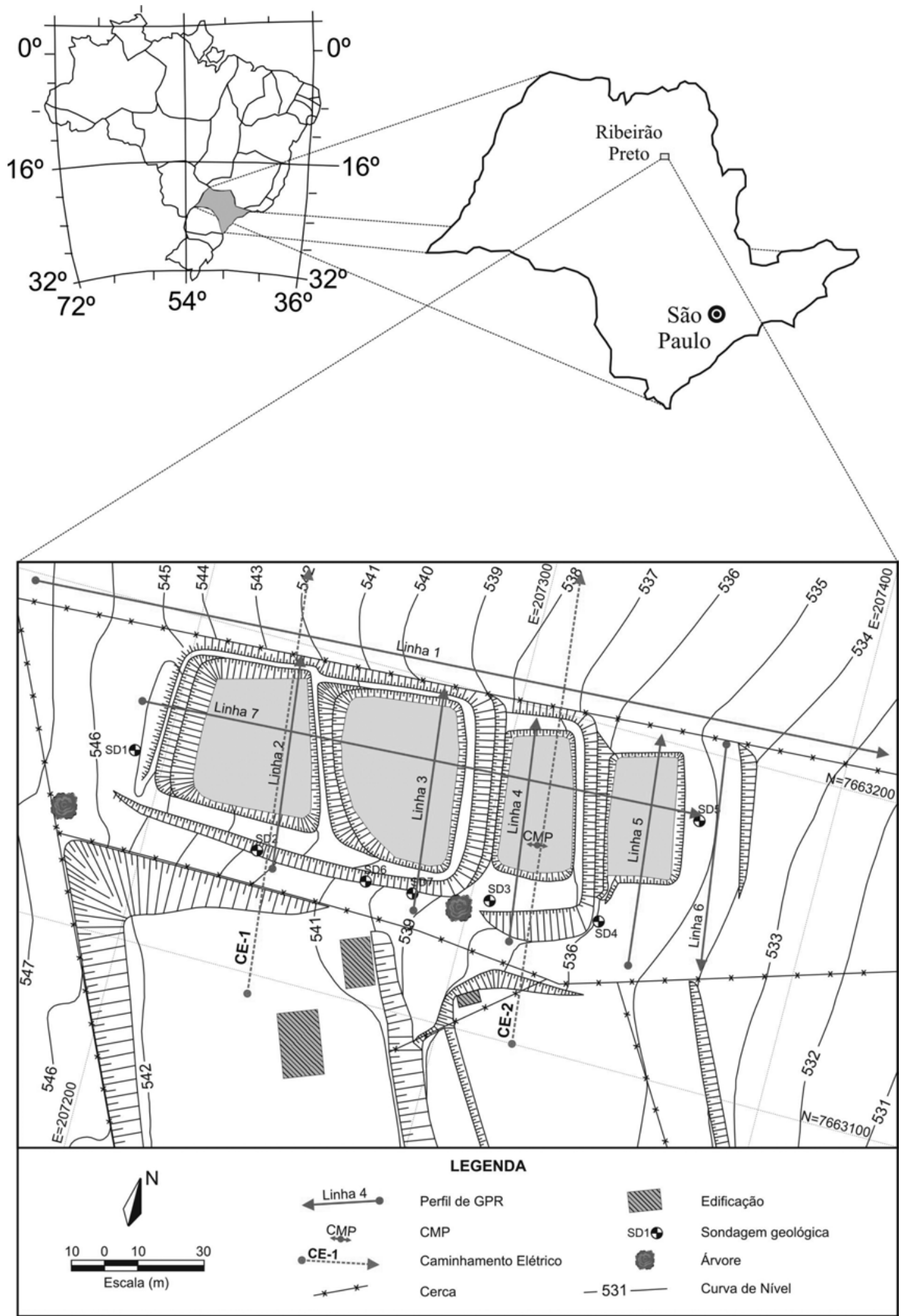

Figura 2 - Localização da área em estudo e dos perfis geofísicos. 


\section{METODOLOGIA}

0 georadar ou GPR é um método geofísico que emprega ondas eletromagnéticas nas freqüências entre 10 e 2000 MHz, para localizar estruturas e feições geológicas rasas (Davis \& Annan, 1989; Annan, 1992).

Este método consiste na emissão e recepção de ondas eletromagnéticas refletidas nas interfaces do meio físico, produzindo como resultado uma imagem de alta resolução da subsuperfície. Os principais fatores que controlam 0 sinal do georadar são: a freqüência e a velocidade da onda eletromagnética no meio, o coeficiente de reflexão (contraste de permissividade dielétrica entre os meios) e a atenuação do meio. A atenuação é proporcional à condutividade elétrica do meio, de forma que quanto maior a condutividade maior a atenuação da onda eletromagnética (Annan, 1992).

As técnicas convencionais de aquisição de dados são common offset (afastamento constante) e a sondagem de velocidade. A mais utilizada é a common offset, onde um par de antenas (uma transmissora e outra receptora) é deslocado ao mesmo tempo ao longo de um perfil. As sondagens de velocidade mais comuns são a Common Mid Point-CMP e Wide Angle Reflection and Refraction - WARR. Na técnica CMP, a abertura entre as antenas (transmissora e receptora) é crescente em sentidos opostos, partindo-se de um ponto central fixo. Na técnica WARR, uma das antenas é mantida fixa enquanto a outra é sucessivamente afastada da primeira.

A coleta de dados GPR foi realizada dentro e fora das cavas, com 0 intuito de verificar a existência e o comportamento do contaminante no subsolo. Os dados adquiridos no modo common offset perfazem 7 seções (Figura 2). 0 equipamento utilizado foi o RAMAC I, fabricado pela empresa Mala Geoscience, do Departamento de Geofísica do IAG/USP. Foi utilizado um par de antenas não-blindadas de $100 \mathrm{MHz}$ sobre um trenó de PVC desenvolvido pelo LIGA (Laboratório de Instrumentação Geofísica) do IAG. Os parâmetros de aquisição utilizados foram: espaçamento entre traços de 0,2 metros, freqüência de amostragem de $1640 \mathrm{MHz}$, empilhamento de 32 traços, e os disparos e registros dos traços coletados continuamente com a utilização de um odômetro (Figura 3). Uma sondagem de velocidade do tipo CMP foi adquirida na cava 3 com um par de antenas não blindadas de $200 \mathrm{MHz}$, espaçamento entre traços de 0,05 metros, empilhamento de 32 e frequêencia de amostragem de aproximadamente $2900 \mathrm{MHz}$.

Os dados foram processados no software ReflexW, versão 4.0 (Sandmeier, 2006). A rotina de processamento consistiu em con- versão de formato do arquivo, ajuste do tempo zero, filtros temporal (dewow e passa-banda), ganhos (linear e exponencial), conversão em profundidade (velocidade constante) e correção topográfica. Os mesmos parâmetros de ganho e filtros foram aplicados a todas as seções com o intuito de comparação das amplitudes dos sinais.

A velocidade média de propagação da onda eletromagnética, dentro das cavas, foi determinada pelo método da semblance (Yilmaz, 1987). A Figura 4a mostra o modelo de velocidade obtido com 0 ajuste do refletor hiperbólico encontrado a 44 ns. A Figura $4 b$ mostra 0 traço resultante do empilhamento da CMP após a correção normal moveout - NMO. A Figura 4c mostra a CMP e os principais eventos identificados (ondas aérea, direta no solo e refletida), e a Figura $4 \mathrm{~d}$ mostra 0 espectro de velocidade indicando a máxima coerência do refletor na posição de 44 ns. Nota-se no espectro de velocidades que há um "estiramento" nos valores de máxima coerência de velocidade no intervalo entre 0,08 e 0,02 m/ns (Figura 4d). De acordo com Yilmaz (1987) este efeito de "estiramento" é comumente provocado quando a correção NMO é realizada em CMP's que possuem pequenos offsets. Entretanto, a máxima coerência de velocidade está centrada em 0,089 m/ns, a qual foi utilizada para conversão das seções em tempo para profundidade.

\section{RESULTADOS E DISCUSSÕES}

Nenhuma investigação indireta permitiu alcançar e identificar 0 nível d'água, que de acordo com Penner (2005) está por volta de 12 a 16 metros de profundidade, deste modo, todas as interpretações realizadas neste trabalho referem-se a zona nãosaturada.

A Linha 1 mostra 0 perfil de GPR realizado fora das cavas (Figura 5). Nesta seção, o sinal eletromagnético foi bem atenuado, não permitindo investigar profundidades superiores a 10 metros. A seção GPR da Figura 5 apresenta várias seqüências de refletores plano-paralelos lateralmente descontínuos, as quais revelam a estruturação interna do solo argilo-siltoso até aproximadamente 10 metros.

A Figura 6a mostra a Linha 2 de GPR. Esta seção foi realizada sobre a cava 1 e possui 58 metros de extensão. Os refletores entre as posições 20,8 e 52 metros mostram um aumento na amplitude a partir da cota de 543 metros. Este aumento é provocado pelo aumento da resistividade elétrica do resíduo. Abaixo do resíduo, a partir da cota de 540 metros, a amplitude dos refletores vai diminuindo, não permitindo identificar a base da cava. Nota-se que este comportamento só ocorre abaixo da cava, não se estendendo 


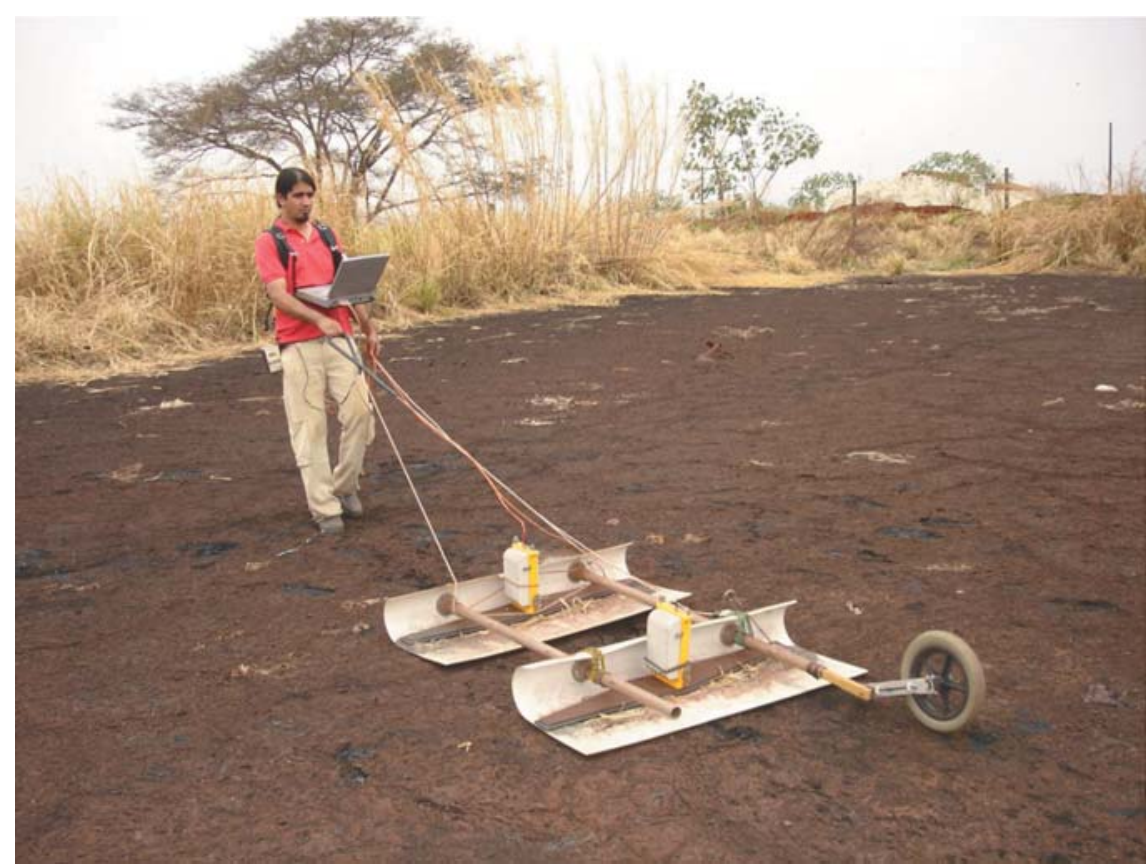

Figura 3 - Aquisição de dados GPR utilizando antenas não-blindadas de $100 \mathrm{MHz}$ (Ramac I, Mala Geoscience) sobre um trenó de PVC e odômetro.

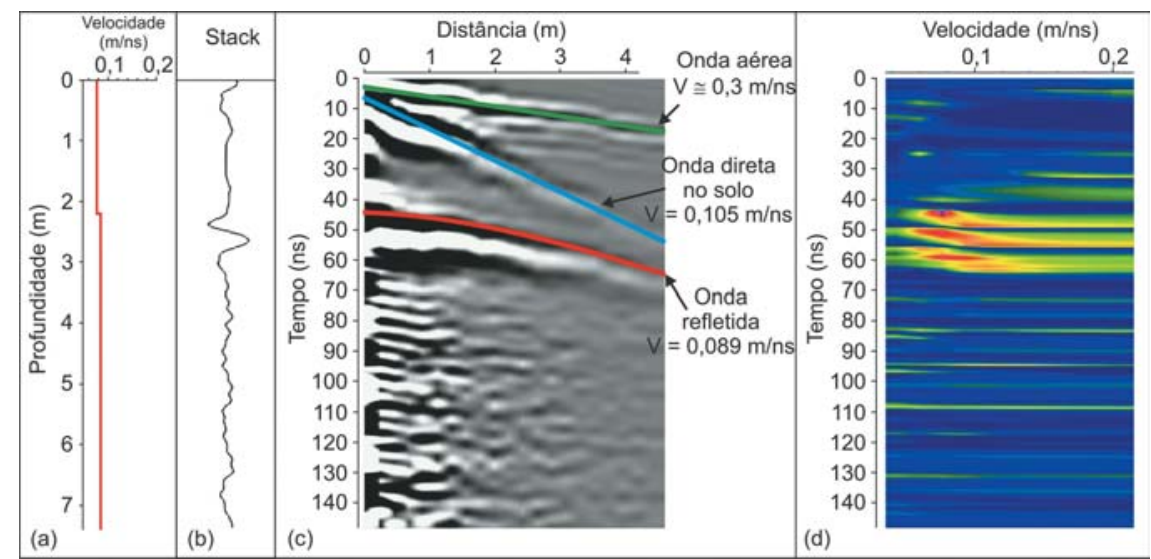

Figura 4 - Análise de velocidade da CMP realizada sobre a cava 3. (a) Modelo de velocidade. (b) Traço empilhado da CMP. (c) Sondagem de velocidade CMP com os principais eventos identificados. (d) Análise de semblance mostrando a velocidade de maior coerência do refletor hiperbólico.

para as laterais. Penner (2005) e Lago et al. (2006) utilizando eletrorresistividade verificaram que 0 resíduo mostra valores de resistividade elétrica acima de $1000 \Omega . m$, e que abaixo das cavas a resistividade diminui para menos de $50 \Omega$.m. Estes baixos valores de resistividade explicam o comportamento do sinal eletromagnético dentro das cavas. De acordo com Sauck (2000), 0 ataque de bactérias a hidrocarbonetos pode causar 0 aumento da condutividade elétrica do meio. No entanto, análises realizadas em amostras de resíduos das cavas (Penner, 2005) mos- tram valores de pH de 0,1, sendo classificado como um meio extremamente ácido. Esta acidez pode ter dissolvido a fração coloidal do solo argilo-siltoso, aumentando assim, a quantidade de sólidos totais dissolvidos e a condutividade elétrica do meio. As duas interpretações são apenas hipóteses que podem explicar 0 fenômeno que ocorre abaixo das cavas, não sendo confirmadas neste trabalho. 0 fato é que abaixo das cavas, a condutividade elétrica do meio é maior, o que dificulta a penetração da onda EM. 


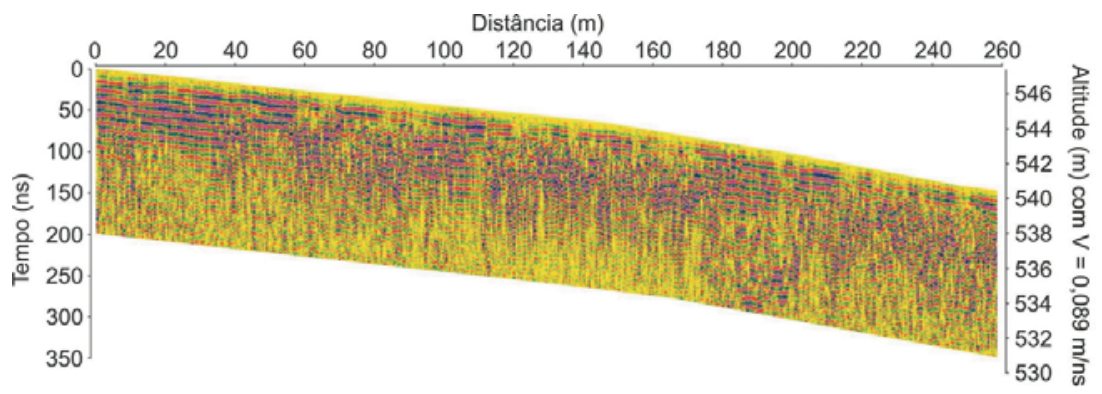

Figura 5 - Seção GPR da Linha 1, realizada fora da área de disposição dos resíduos.

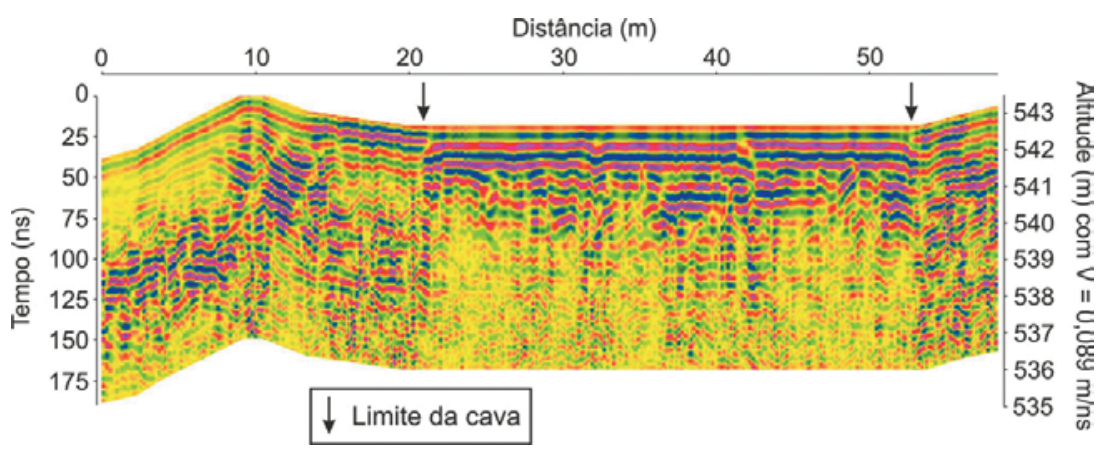

Figura 6 - Seção GPR da Linha 2 realizada sobre a cava 1.

A Figura 7 mostra a seção GPR da Linha 3 que foi realizada sobre a cava 2. A cava é bem marcada no intervalo de 21,7 a 61 metros. 0 resíduo apresenta um comportamento horizontal e com forte reflexão, evidenciando sua homogeneidade. A base da cava 2 é bem marcada por um forte refletor irregular que ocorre na cota de 538 metros (Figura 7 - linha pontilhada). Na posição de 26 metros, na cota de 538 metros ocorre um expressivo refletor hiperbólico. Este refletor pode ser provocado por um tanque disposto na área ou por qualquer outro objeto pontual que cause difração do sinal GPR. A velocidade do meio, obtida através do ajuste hiperbólico da difração, foi de $0,072 \mathrm{~m} / \mathrm{ns}$, confirmando 0 aumento da condutividade elétrica abaixo da cava.

A Linha 4 de GPR foi realizada sobre a cava 3, como mostra a Figura 8, onde identifica-se 0 resíduo entre as posições de 26 e 57 metros. Nesta seção, além da verificação da base da cava na cota de 534,7 metros (linha tracejada), percebem-se também variações na amplitude dos refletores dentro da cava, sugerindo heterogeneidades no resíduo. Notam-se reflexões hiperbólicas no interior do resíduo nas posições de 40,5 m (cota 536,5 metros), 51 e $52,5 \mathrm{~m}$ (cota 536,5 metros, podendo ser provocadas por tambores metálicos, comumente utilizados para transporte de resíduos e bem evidenciados na superfície da cava 4 (Figura 9).

A Figura 10 mostra o perfil de GPR realizado sobre a cava
4 (Linha 5). A base da cava é bem marcada por um refletor em forma de vale que ocorre entre as posições de 31 a 60 metros, alcançando a profundidade máxima de 5,45 metros na posição de 48 metros (linha tracejada). Nas posições de 46 e 47,8 metros, na profundidade de 0,5 metros notam-se dois refletores hiperbólicos que podem indicar a presença de tambores metálicos. Abaixo da base da cava, semelhante a todas as cavas, o sinal eletromagnético é fortemente atenuado.

Com o intuito de verificar se existe fluxo de contaminante subterrâneo na zona não-saturada em função do desnível topográfico, foi adquirida uma seção GPR próxima a cava 4 (Linha 6). Na seção GPR (Figura 11), os refletores apresentaram o mesmo comportamento e amplitude da seção da Linha 1, não evidenciando a presença de contaminantes orgânicos na zona aerada do solo, confirmando o resultado de análises químicas de solos coletados nas sondagens SD3 e SD5 (Penner, 2005).

Para definir a geometria e verificar a existência de contaminante abaixo das cavas, foi realizada uma seção GPR (Linha 7) perpendicular a todas as cavas, mostrada na Figura 12. Com exceção da cava 1, todas as bases das demais cavas foram bem marcadas no perfil. A base da cava 2 vai aprofundando em direção leste e a cava 3 e 4 tem a base da cava retilínea (Figura 12b). Em toda a seção, 0 sinal eletromagnético GPR foi atenuado abaixo das 


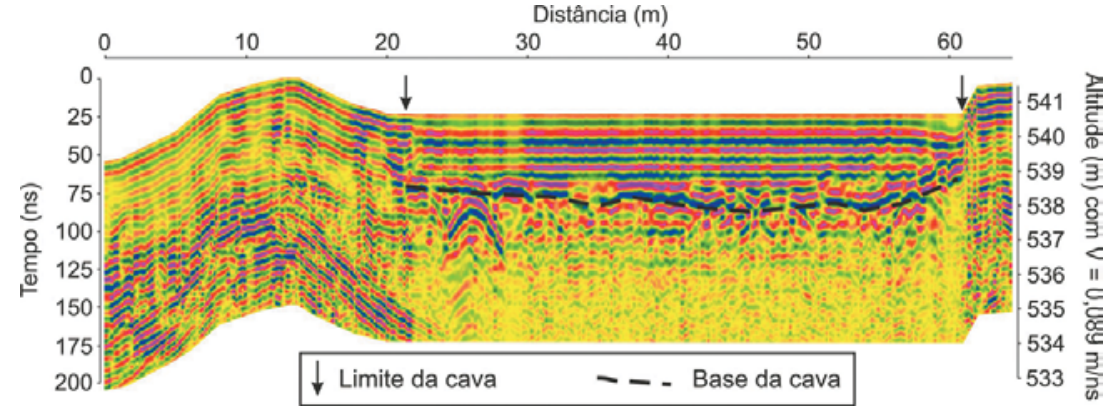

Figura 7 - Seção GPR da Linha 3 realizada sobre a cava 2, mostrando limites da cava, refletores correlacionados a tanques/tambores e atenuação do sinal EM abaixo da cota de 538 metros.

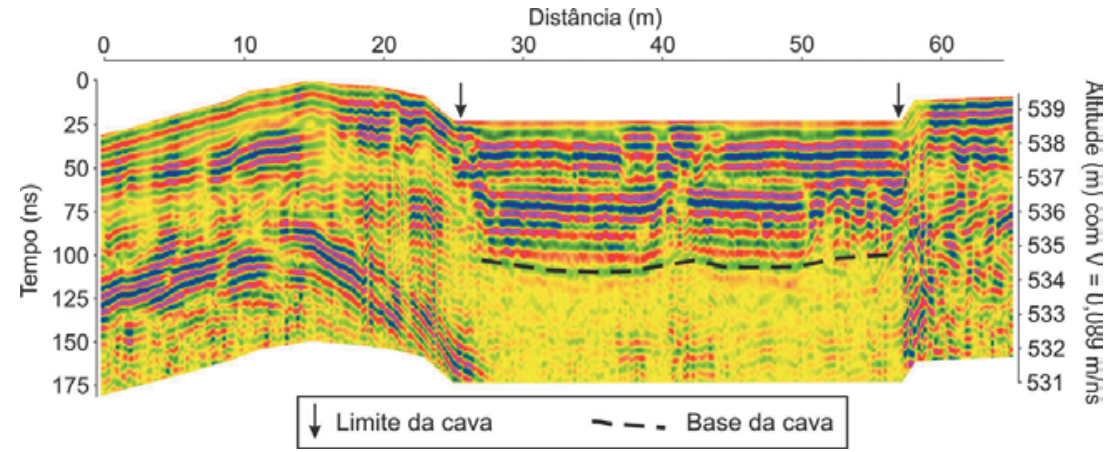

Figura 8 - Seção GPR da Linha 4 realizada sobre a cava 3, mostrando limites da cava e atenuação do sinal EM abaixo da cota de 534,5 metros.

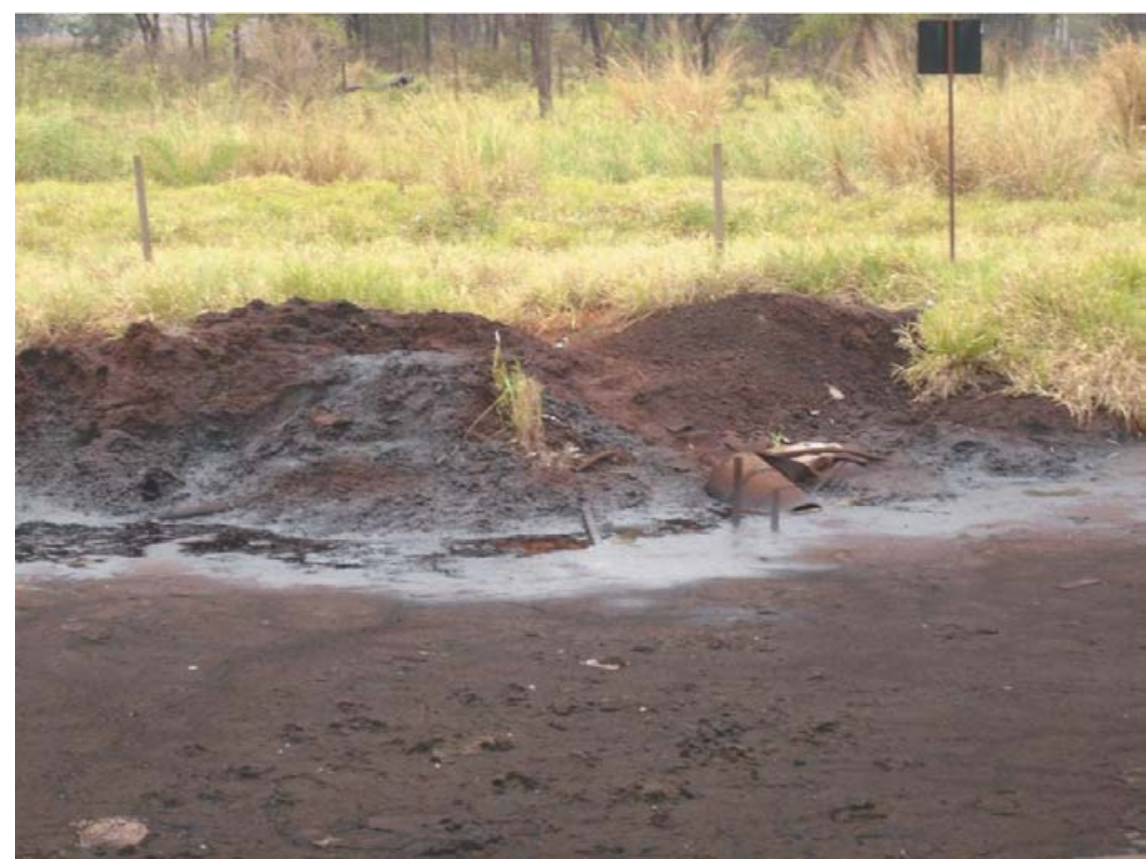

Figura 9 - Cava 4 preenchida com resíduos e alguns tambores dispostos em superfície. 


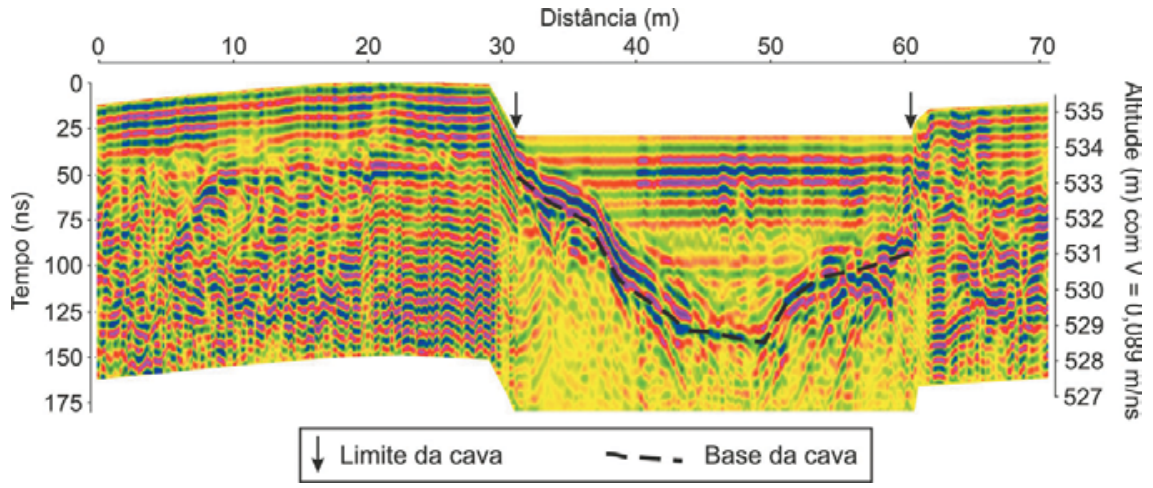

Figura 10 - Seção GPR realizada sobre a cava 4, marcando limites e base da cava (profundidade máxima de 5,45m) representada por um refletor em forma de vale.

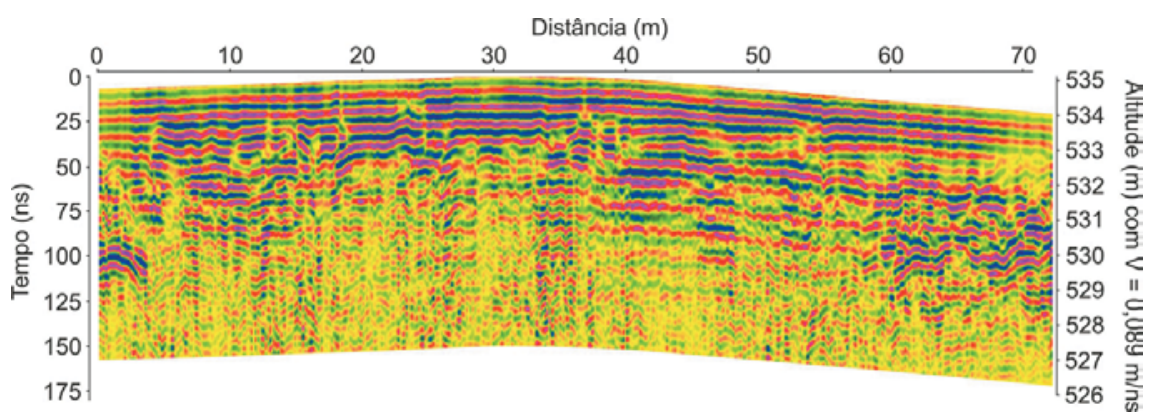

Figura 11 - Seção GPR realizada sobre a linha 6 (fora das cavas). Não há indícios de atenuação nesta seção, provocada por contaminação.
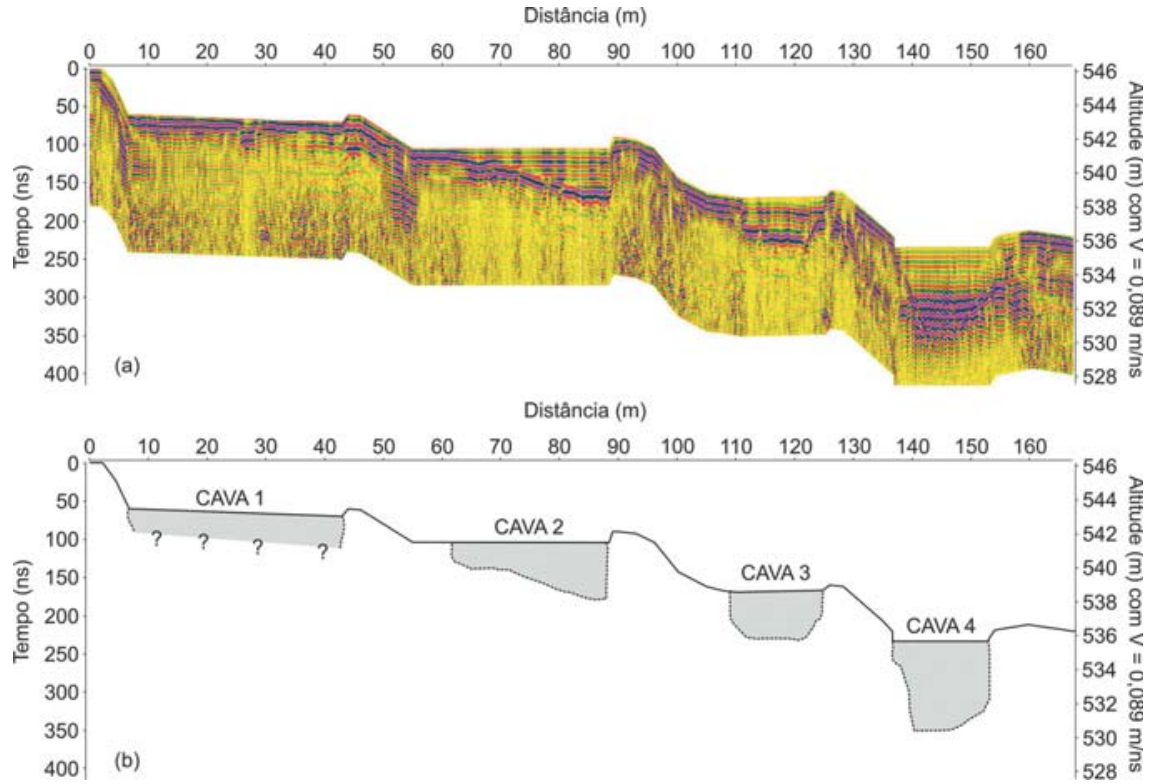

Figura 12 - (a) Seção GPR realizado perpendicularmente a todas as cavas. (b) Modelo interpretado a partir da atenuação do sinal EM, marcando assim os limites e as bases das cavas. 
cavas, corroborando com os resultados das seções anteriores.

Após verificar o comportamento do sinal GPR dentro e abaixo das cavas, notamos que a cava 1 possui comportamento distinto das demais, deste modo, para auxiliar nas interpretações de GPR foram adquiridos 2 perfis de tomografia elétrica de superfície, sobre a cava $1 \mathrm{e} 3$ (Figura 2). Os perfis foram realizados em direção a NW da área, arranjo eletródico dipolo-dipolo, espaçamento entre os dipolos de 10 metros e 6 níveis de investigação. 0 equipamento utilizado foi 0 Syscal R2, fabricado pela empresa francesa IRIS, de propriedade do Departamento de Geofísica do IAG/USP. Para diminuir o tempo de aquisição de cada perfil, foi utilizado um comutador eletrônico de eletrodos desenvolvido no Laboratório de Instrumentação Geofísica do Departamento de Geologia do IAG/USP (Hiodo et al., 2001). Os dados de resistividade elétrica aparente foram modelados no software Res2dinv (Loke, 2004).

A Figura 13a mostra o modelo de resistividade da linha CE1 (realizada sobre a cava 1), foram individualizados duas unidades geolétricas, uma resistiva (> $500 \Omega$.m) e uma condutiva (> $150 \Omega$ S.m). A primeira unidade ocorre fora das cavas, ao passo que a segunda ocorre dentro e abaixo da cava 1.0 modelo geolétrico da CE2 (realizada sobre a cava 3, Figura 13b) possui um comportamento semelhante ao verificado na CE1, entretanto, os valores de resistividade elétrica sobre 0 resíduo são mais elevados (> $500 \Omega$.m). Nota-se desta forma, que no modelo geolétrico obtido sobre a cava 1 é difícil distinguir entre o resíduo (cava) e a fase residual, pois mostram resistividades iguais. Todavia os resultados obtidos sobre a cava 3 permitem diferenciar, através do contraste de resistividade elétrica, o resíduo da fase residual.

As Figuras 14a e 14b mostram os modelos geológicosgeoquímicos elaborados, para a cava $1 \mathrm{e} 3$, a partir dos resultados de GPR e eletrorresistividade. Nos modelos, a base das cavas foi estabelecida com os resultados de GPR e a zona de percolação do resíduo (fase residual) definida com os dados de resistividade elétrica.

\section{CONCLUSÕES}

0 GPR mostra eficiência no mapeamento da geometria das cavas, identificando os limites e a base das cavas preenchidas com resíduos provenientes de óleo lubrificante. A zona de absorção de energia eletromagnética localizada abaixo das cavas está relacionada com o aumento da condutividade elétrica do meio, deste modo, aquisiç̧ões de eletrorresistividade são essenciais para auxiliar nas interpretações.

Além disto, os dados GPR possibilitaram a identificação de objetos difratores (talvez tambores e/ou tanques) dentro do resíduo, confirmando sua aplicabilidade na área.

Os resultados obtidos com a eletrorresistividade permitiram a distinção entre o resíduo (presente nas cavas) e o percolado na zona aerada (fase residual).

Apesar dos resultados obtidos com a tomografia elétrica com o dipolo de 10 metros, em áreas com cavas com dimensões semelhantes a deste trabalho, sugerimos a realização de aquisições elétricas com espaçamento entre os dipolos de 5 metros, para resolver melhor a geometria das cavas.

\section{AGRADECIMENTOS}

Ao Sr. Sérgio Barbieri pela autorização de acesso a área de pesquisa. Ao Dr. Giovanni Chaves Penner pelo empréstimo de mapas cartográficos e dados geológicos da região. A CAPES/PROAP pelo apoio financeiro nas etapas de campo. Ao IAG/USP pela oportunidade de desenvolvimento da pesquisa. Aos revisores anônimos pelas valiosas sugestões que auxiliaram no aprimoramento deste artigo.

\section{REFERÊNCIAS}

ANNAN AP. 1992. Ground penetration radar workshop notes. Sensors \& Software, Inc., Internal Report, 130 pp.

ATEKWANA EA, SAUCK WA \& WERKEMA Jr DD. 2000. Investigations of geoelectrical signatures at a hydrocarbon contaminated site. Journal of Applied Geophysics, 44: 167-180.

BENSON AK. 1995. Applications of ground penetrating radar in assessing some geological hazards: examples of groundwater contamination, faults, and cavities. Journal of Applied Geophysics, 33: 177-193.

CASTRO DL de \& BRANCO RMGC. 2003. 4-D ground penetrating radar monitoring of a hydrocarbon leakage site in Fortaleza (Brazil) during its remediation process: a case history. Journal of Applied Geophysics, 54: 127-144.

COMMITTEE ON SOURCE REMOVAL OF CONTAMINANTS IN THE SUBSURFACE. 2004. Contaminants in the Subsurface: Source Zone Assessment and Remediation. National Research Council. 372 pp.

CETESB. COMPANHIA DE TECNOLOGIA DE SANEAMENTO AMBIENTAL. 2001. Manual de Gerenciamento de Áreas Contaminadas. Projeto de Cooperação Técnica Brasil-Alemanha/CETESB-GTZ. 2. ed., São Paulo, 398 pp

DANIELS JJ, ROBERTS R \& VENDL M. 1995. Ground penetrating radar for the detection of liquid contaminants. Journal of Applied Geophysics, 33: 195-207. 


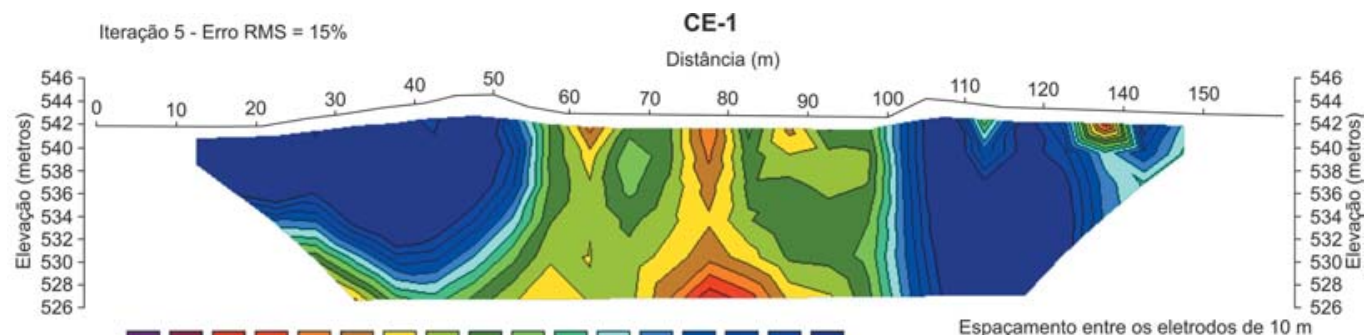

(a)

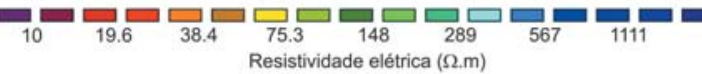

Espaçamento entre os eletrodos de $10 \mathrm{~m}$ Resistividade elétrica $(\Omega \cdot \mathrm{m})$

Iteraçăo 5 - Erro RMS $=43,9 \%$

CE-2

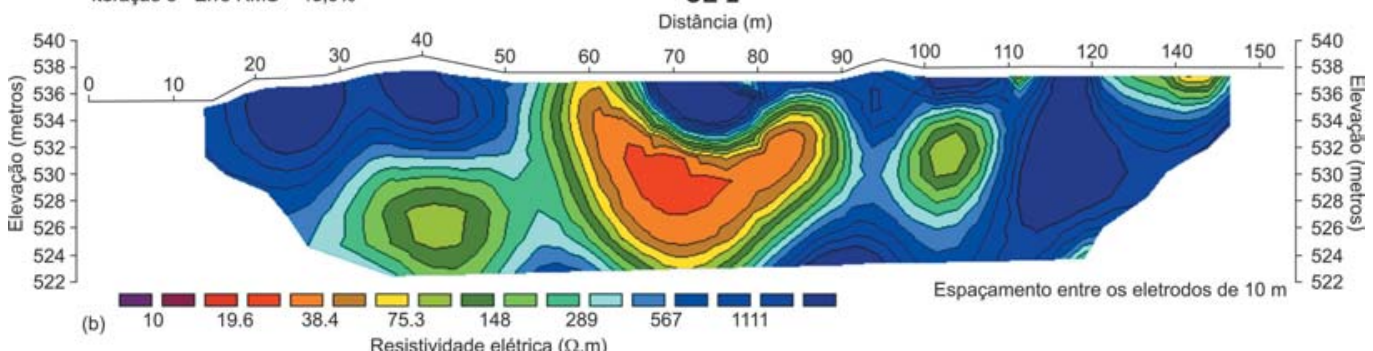

Figura 13 - Seções de tomografia elétrica 2D executadas na área. (a) Linha CE-1 adquirida na cava 1, e (b) Linha CE-2 sobre a cava 3.

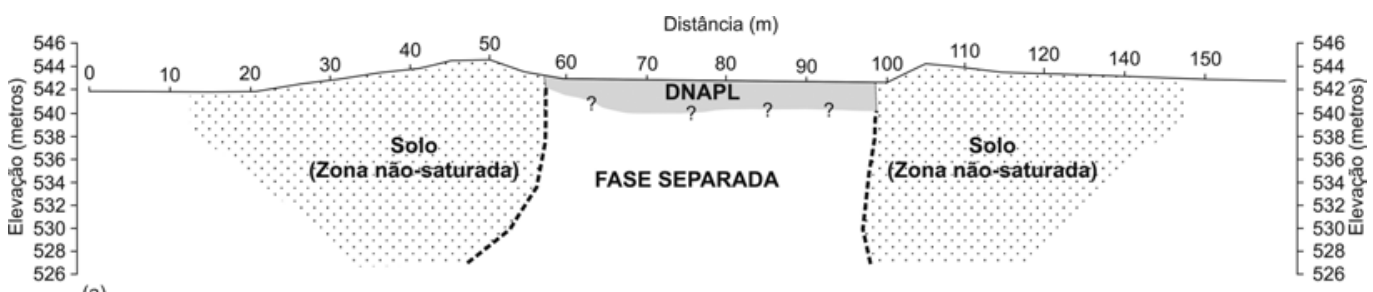

(a)

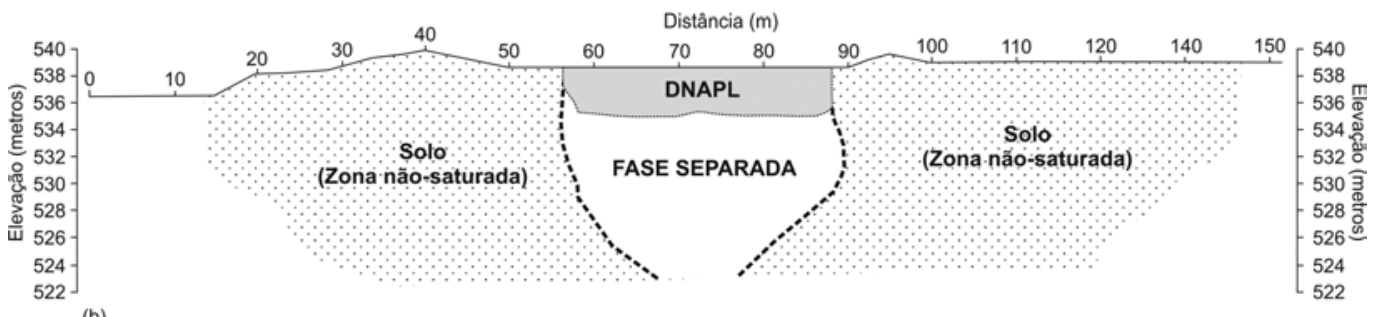

Figura 14 - Modelos geológicos-geoquímicos elaborados, para a cava 1 (a) e 3 (b), a partir dos resultados de GPR e eletrorresistividade.

DAVIS JL \& ANNAN AP. 1989. Ground Penetrating Radar for High Resolution Mapping of oil and rock stratigraphy. Geophysical Prospecting, 37: $531-551$

DEHAINE J. 2001. Detecção da pluma de contaminação de hidrocarbonetos em subsuperfície pelo método de radar de penetração. Tese de Doutorado, IGc/USP, São Paulo, 100 pp.

FREEZE RA \& CHERRY JA. 1979. Groundwater. Prentice-Hall International Inc. Englewood Cliffs, New Jersey, 604 pp.

HIODO FY, SILVA N, ELIS VR, GALHARDO FILHO L \& SILVA JE da.
2001. Projeto de um sistema semi-automatizado de medidas de potencial elétrico natural ou induzido do solo para aplicações geolétricas. Anais do $7^{\circ}$ International Congress of the Brazilian Geophysical Society, Salvador, BA, p. 136-139.

LAGO AL, ELIS VR, BORGES WR, FACHIN SJ da S \& SANTOS EC. 2006. Aplicação do método da eletrorresistividade em uma área de disposição de resíduos de óleos lubrificantes. Anais do II Simpósio Brasileiro de Geofísica, Natal, RN. CD-ROM.

LOKE MH. 2004. Res2Dinv v. 3.54 for Windows 98/Me/2000/ NT/XP. Rapid 2D Resistivity \& IP Inversion using the least-squares method. Soft- 
ware Manual. 133 p. Disponível em: <http://www.geoelectrical.com> Acesso em: 14 mar. 2005.

PENNER GCE. 2005. Estudo de caso da contaminação do solo e da água subterrânea por deposição no solo de resíduos vinculados a óleos lubrificantes. Tese de Doutorado (Escola de Engenharia de São Carlos), USP, São Carlos, 193 pp.

ROSSELI ML. 1995. Avaliação Hidrogeológica e Programa de Monitoramento da Água Subterrânea. Córrego do Campo, Ribeirão Preto, SP, $22 \mathrm{pp}$.

SANDMEIER KJ. 2006. REFLEXW Version 4.0 for Windows 9x/2000/ NT/XP. Program for the processing of seismic, acoustic or electromagnetic reflection, refraction and transmission data. Manual do Software, $192 \mathrm{pp}$.
SAUCK WA. 2000. A model for the resistivity structure of LNAPL plumes and their environs in sandy sediments. Journal of Applied Geophysics, 44: 151-165.

SAUCK WA, ATEKWANA EA \& NASH MS. 1998. High conductivities associated with an LNAPL plume imaged by integrated geophysical techniques. Journal of Environmental and Engineering Geophysics, 2(3): 203-212.

VICKERY AC \& HOBBS BA. 1998. Contributions of surface geophysics to environmental site investigation of former oil distribution terminals. Journal of Environmental and Engineering Geophysics, 3(3): 101-109.

YILMAZ 0. 1987. Seismic data processing. Tulsa: Society of Exploration Geophysics Press, 526 pp.

\section{NOTAS SOBRE OS AUTORES}

Welitom Rodrigues Borges é geólogo pelo Instituto de Ciências Exatas e da Terra da Universidade Federal de Mato Grosso (ICET/UFMT), em 2000. Em 2002, obteve o título de Mestre em Ciências, área de Geofísica Aplicada, pelo Instituto de Astronomia, Geofísica e Ciências Atmosféricas da Universidade de São Paulo (IAG/USP). Atualmente, é doutorando junto ao Programa de Pós-Graduação do IAG/USP. Desenvolve a pesquisa "Caracterização geofísica de alvos rasos com aplicações no planejamento urbano, meio ambiente e arqueologia: Estudo sobre o sítio controlado do IAG/USP". Trabalha ainda com processamento de dados sísmicos e eletromagnéticos no Laboratório de Geofísica Computacional (LGC/IMEC) da Unicamp.

Alexandre Lisboa Lago é geólogo pelo Instituto de Geociências da Universidade Federal do Pará (IG/UFPA), em 1997. Em 2004, obteve o título de Mestre em Ciências, área de Geofísica Aplicada, pelo Instituto de Astronomia, Geofísica e Ciências Atmosféricas da Universidade de São Paulo (IAG/USP). Atualmente, é doutorando junto ao Programa de Pós-Graduação em Geofísica do IAG/USP, desenvolvendo a pesquisa "Investigação Geofísica 3D com aplicação em meio ambiente: Estudo sobre uma área de disposição de resíduos de óleo automotivo em Ribeirão Preto-SP".

Sergio Junior da Silva Fachin é geólogo pelo Instituto de Ciências Exatas e da Terra da Universidade Federal de Mato Grosso (ICET/UFMT), em 2005. Entre os anos de 2001 a 2005, foi integrante do Núcleo de Geofísica e Estudos Ambientais da UFMT, participando de projetos em Geofísica Aplicada (Métodos elétricos, eletromagnéticos aplicados à Geologia, Geotecnia, Hidrogeologia e Meio Ambiente). Atualmente é mestrando em Geofísica Aplicada pelo Instituto de Astronomia, Geofísica e Ciências Atmosféricas da Universidade de São Paulo (IAG/USP), desenvolvendo a pesquisa "Mapeamento geoelétrico temporal 2D no antigo Lixão de Ribeirão Preto - SP".

Vagner Roberto Elis é graduado em Geologia, em 1990, pela Universidade Estadual Paulista. Mestre em Geociências pela Universidade Estadual Paulista, em 1993, desenvolvendo a dissertação "A aplicação da geofísica para análise do meio físico: Importância para elaboração de mapeamento geotécnico". Doutor em Geociências pela Universidade Estadual Paulista, em 1999, defendendo a tese "Avaliação da aplicabilidade de métodos elétricos de prospecção geofísica no estudo de áreas utilizadas para disposição de resíduos". Atualmente, é docente do Departamento de Geofísica do IAG/USP, atuando nas áreas de Geofísica Aplicada a estudos ambientais e hidrogeológicos.

Ernande Costa Santos é técnico do Laboratório de Geofísica Aplicada do IAG/USP, desde 1999. Desenvolve atividades de aquisição de dados topográficos, elétricos, eletromagnéticos, magnéticos, radiométricos e sísmicos. 